Check for updates

Cite this: RSC Adv., 2019, 9, 36410

Received 20th August 2019

Accepted 31st October 2019

DOI: $10.1039 / c 9 r a 06524 \mathrm{e}$

rsc.li/rsc-advances

\section{A stimuli responsive triplet-triplet annihilation upconversion system and its application as a ratiometric sensor for $\mathrm{Fe}^{3+}$ ions ${ }^{\dagger}$}

\author{
Shuoran Chen, (D) a Fuming Chen, ${ }^{a}$ Pengju Han, (D) *a Changqing Ye, (D) *a \\ Suqin Huang, ${ }^{a}$ Lei $\mathrm{Xu}{ }^{\mathrm{a}}$ Xiaomei Wang ${ }^{\mathrm{a}}$ and Yanlin Song $\mathbb{D}^{\mathrm{b}}$
}

A ratiometric fluorescent sensor for the detection of $\mathrm{Fe}^{3+}$ ions is achieved based on triplet-triplet annihilation upconversion (TTA-UC) luminescence. A new anthracene derivative (named as DHTPA) is designed and synthesized and reveals similar optical properties to 9,10-diphenylanthracene (DPA) and is used as a stimuli responsive annihilator in a TTA-UC system due to its complexation ability. As a result, the UC emission can be significantly quenched by $\mathrm{Fe}^{3+}$ ions, while the phosphorescence (PL) emission of sensitizer palladium(॥) octaetylporphyrin (PdOEP) remains nearly constant, which makes the PL signal an appropriate internal reference for the UC signal. The UC and ratio signals $\left(/_{U C} / /_{\mathrm{PL}}\right)$ both reveal a good linear relationship with $\mathrm{Fe}^{3+}$ ion concentration, which for the first time makes the TTA-UC system a perfect ratiometric sensor for $\mathrm{Fe}^{3+}$ ion detection. This sensing method will open a novel avenue to achieve ratiometric sensors in chemical and biological fields.

\section{Introduction}

As a class of trace elements, metals play significant roles in the constitution and metabolism of living organisms. ${ }^{1}$ The imbalance of metal elements can cause various diseases. ${ }^{2}$ As the main uptake form of iron, $\mathrm{Fe}^{3+}$ is the key component of haemoglobin and myoglobin for oxygen transport and of enzymes for metabolism balance of tissue cells. ${ }^{3}$ Nevertheless, long-term excess uptake of $\mathrm{Fe}^{3+}$ will cause detrimental effects to tissues and organs, ${ }^{4}$ eventually resulting in neurodegenerative diseases ${ }^{5}$ such as Alzheimer's $s^{6}$ and Parkinson's. ${ }^{7}$ Thus, it is of great significance to keep $\mathrm{Fe}^{3+}$ ions inside human and animal bodies at normal levels. Unfortunately, iron has been overly and inappropriately used in areas including manufacturing, ${ }^{8}$ architecture ${ }^{9}$ and agriculture, ${ }^{10}$ causing high concentrations of iron, mainly $\mathrm{Fe}^{3+}$, gradually emerging in living regions, especially in domestic water. ${ }^{11}$ Therefore, it is urgent to develop efficient methods for the detection of $\mathrm{Fe}^{3+}$ ions in environmental samples.

Among all the reported strategies on $\mathrm{Fe}^{3+}$ detection including electrochemical process, ${ }^{12}$ atomic absorption spectrometry, ${ }^{13}$ nanosensors ${ }^{14}$ and fluorescent spectrometry, ${ }^{15}$ molecular fluores

${ }^{a}$ Research Centre for Green Printing Nanophotonic Materials, Jiangsu Key Laboratory for Environmental Functional Materials, Institute of Chemistry, Biology and Materials Engineering, Suzhou University of Science and Technology, Suzhou 215009, P. R. China. E-mail: yechangqing@mail.usts.edu.cn

${ }^{b}$ Key Laboratory of Green Printing, Institute of Chemistry, Chinese Academy of Sciences, Beijing 100190, P. R. China

† Electronic supplementary information (ESI) available. See DOI: 10.1039/c9ra06524e -cent probes have attracted great research attention due to their high simplicity, selectivity, sensitivity and response rate. Selective weak interaction or complexation may occur between molecular probes and $\mathrm{Fe}^{3+}$ ions, leading to the change of molecular structure of the probes and the corresponding varying of the fluorescent signals (e.g. fluorescence intensity, shift or lifetime). ${ }^{16}$

In the past decades, considerable efforts have been devoted to the development of fluorescent probes for $\mathrm{Fe}^{3+}$ ions. ${ }^{17}$ The majority of the reported probes are based on traditional downconverting fluorescence of dyes excited under UV or visible irradiation, ${ }^{18}$ which have drawbacks including low media penetration and potential harm to human health. Besides, autofluorescence derived from fluorescent proteins ${ }^{19}$ or other biological fluorescein ${ }^{20}$ in the biological samples will in turn interfere the detection signals of the probes. ${ }^{21}$ Whereas, all above issues can be solved by using photoluminescent probes based on frequency upconversion (UC) ${ }^{22}$ which is a process converting low energy photons to higher ones. The long wavelength excitation brings good penetrability, which makes UC a useful probe in many complicated application environments. Besides, it can avoid the harm from common UV excitation irradiation, either to organism or chromophore structure. ${ }^{23}$ Among all the present mechanisms of UC, triplet-triplet annihilation upconversion (TTA-UC) has drawn widely research interests due to its relatively higher $(>10 \%)$ quantum yield (QY) and lower $\left(<10 \mathrm{~mW} \mathrm{~cm}^{-2}\right)$ threshold excitation intensity $\left(I_{\text {th }}\right) .^{24}$ Particularly, TTA-UC is a double-dye system consisting of triplet sensitizers and annihilators, which may simultaneously cause two photoluminescent emissions from the two kinds of dyes. Briefly, when exciting light of specific wavelength irradiating the TTA-UC system, the UC 
luminescence through a triplet-triplet energy transfer (TTET) process from sensitizer to annihilator and the phosphorescence luminescence (PL) of sensitizer itself occur at the same time. ${ }^{25}$ Interestingly, the UC and PL signals may show different responsive behaviours to the external stimulus or environment, which makes a perfect foundation for a ratiometric sensor. It is well-known that ratiometric sensors can eliminate most of the influences like optical properties of solution, concentration of the fluorescent materials and other experimental or instrumental factors. ${ }^{26}$ Great efforts have been made on developing TTA-UC system as a ratiometric platform for sensing oxygen ${ }^{27}$ and temperature. ${ }^{28}$ However, to the best of our knowledge so far, there is still no report on a ratiometric sensor based on TTA-UC for metal-ion detection. This new strategy elaborately utilizes the double-dye nature of the TTA-UC system and does not need to add an external reference, because the UC and PL signals can be internal reference for each other.

Herein, we designed and synthesized a novel annihilator DHTPA to form a TTA-UC system with sensitizer PdOEP. The system can also be exploited as a ratiometric sensor for the detection of $\mathrm{Fe}^{3+}$ ions. While the UC signal was significantly quenched and showed a good linear relationship with the $\mathrm{Fe}^{3+}$ concentration, the PL signal remained constant. This ratiometric sensor also revealed a high selectivity and sensitivity $\left(7.26 \times 10^{-7} \mathrm{M}\right)$ to $\mathrm{Fe}^{3+}$ ions. This method will provide a new angle to build ratiometric sensors for applications in chemical and biological areas.

\section{Experimental}

\section{Materials}

The compounds 4-bromo-2-hydroxybenzaldehyde (98\%, Aladdin), 9,10-anthracenediboronic acid bis(pinacol) ester (97\%, Aladdin), tetrakis(triphenylphosphine)palladium $\left(\mathrm{Pd}\left(\mathrm{PPh}_{3}\right)_{4}\right)(99 \%, \mathrm{~J} \& \mathrm{~K})$, thiosemicarbazide (99\%, Aladdin) and palladium(II) octaetylporphyrin (PdOEP) (Frontier) were used without further purification. The solvents ethanol, dichloromethane, toluene, 1,4-dioxane, petroleum ether and $\mathrm{N}, \mathrm{N}$ dimethylformamide (DMF) were of analytical grade and used as received. HEPES buffer solution (HyClone) was purchased from GE Healthcare Life Sciences. Water was deionized and distilled before use. Other chemicals were all purchased from Sinopharm Chemical Reagent Co., Ltd.

\section{Characterizations}

IR spectra were measured on a Nicolet FT-IR 5DX instrument using solid samples dispersed in potassium bromide $(\mathrm{KBr})$ disks. Mass spectra were measured on a Fourier transform ion cyclotron resonance mass spectrometer (FT-ICR-MS) produced by Bruker Company (bruker solarix X) with 2-[(2E)-3-(4-tertbutylphenyl)-2-methylprop-2-enylidene] malonitrile (DCTB) as the matrix. ${ }^{1} \mathrm{HNMR}$ was measured on an INOVA-400 spectrometer with $\mathrm{THF}-\mathrm{d}_{8}$ with the addition of $\sim 1$ vol\% hydrazine hydrate $\left(\mathrm{N}_{2} \mathrm{H}_{4} \cdot \mathrm{H}_{2} \mathrm{O}\right)$ as solvent.

\section{Spectroscopic measurements}

Absorption spectra were measured on a Shimadzu UV-2600 spectrophotometer. Steady-state fluorescence spectra were measured on an Edinburgh FLS920 fluorophotometer. UC fluorescence spectra were measured on an ideaoptics NOVA fiber spectrometer and an excitation CW laser (532 nm, $60 \mathrm{~mW}$ and $2 \mathrm{~mm}$ beam diameter).

\section{Synthesis}

Synthesis of intermediate product (DHAPA). Under nitrogen atmosphere and stirring condition, $2.84 \mathrm{~g}$ (14.19 mmol) 4bromo-2-hydroxybenzaldehyde and $2 \mathrm{~g}$ (4.72 $\mathrm{mmol})$ 9,10anthracenediboronic acid bis(pinacol) ester were added to a three-necked flask in the presence of $100 \mathrm{~mL}$ 1,4-dioxane and $24 \mathrm{~mL}$ ethanol. When all the reactants were completely dissolved, $9.84 \mathrm{~g}$ (69 mmol) $\mathrm{K}_{2} \mathrm{CO}_{3}$ aqueous solution was added. After refluxing for $15 \mathrm{~min}, 0.39 \mathrm{~g}(1.2 \mathrm{mmol}) \mathrm{Pd}\left(\mathrm{PPh}_{3}\right)_{4}$ was added to the mixture. The reaction extent was tracked by point plate method, and the eluent was dichloromethane/ petroleum ether $(1: 1, \mathrm{v} / \mathrm{v})$. After refluxing for $48 \mathrm{~h}$ under nitrogen atmosphere, 9,10-anthracenediboronic acid bis(pinacol) ester was completely reacted. The mixture was then evaporated under reduced pressure and black powder was obtained. The crude powder was washed and extracted by saturated sodium chloride solution and dichloromethane, respectively. Column chromatography was used for separating the DHAPA after dehydrated by anhydrous sodium sulfate and the eluent was dichloromethane/petroleum ether $(1: 1, \mathrm{v} / \mathrm{v})$. Yellow powder was eventually obtained after recrystallization (1.2 g, yield 60\%). IR (KBr, $\left.\mathrm{cm}^{-1}\right)$ : 3164s $(-\mathrm{OH}), 1700 \mathrm{~s}(\mathrm{C}=\mathrm{O})$ (Fig. S1†). ${ }^{1} \mathrm{HNMR}$ (400 MHz, chloroform- $d$ ) $\delta 11.29(\mathrm{~d}, J=$ $2.9 \mathrm{~Hz}, 2 \mathrm{H}), 10.11(\mathrm{~s}, 2 \mathrm{H}), 7.83(\mathrm{~d}, J=8.0,2.7 \mathrm{~Hz}, 2 \mathrm{H}), 7.72-7.66$ $(\mathrm{m}, 4 \mathrm{H}), 7.41(\mathrm{~d}, J=6.9,3.3 \mathrm{~Hz}, 4 \mathrm{H}), 7.23-7.13(\mathrm{~m}, 4 \mathrm{H})$ (Fig. S4†).

Synthesis of DHTPA. This complex was obtained after reaction of $1 \mathrm{~g}$ (2.39 mmol) DHAPA and $3 \mathrm{~g}(7.17 \mathrm{mmol})$ thiosemicarbazide in the presence of $0.4 \mathrm{~mL}$ acetic acid in the solvent toluene. Continuing refluxing under the nitrogen atmosphere for $24 \mathrm{~h}$ until DHAPA and thiosemicarbazide were completely reacted, the mixture was then evaporated under reduced pressure and black powder was obtained. The crude powder was purified through column chromatography by using dichloromethane/petroleum ether $(1: 1, \mathrm{v} / \mathrm{v})$ as eluent. $0.5 \mathrm{~g}$ faint yellow powder was obtained with yield of $37 \%$. IR ( $\left.\mathrm{KBr}, \mathrm{cm}^{-1}\right)$ : $3188 \mathrm{~s}(-\mathrm{OH}), 1635 \mathrm{~s}(\mathrm{C}=\mathrm{N})($ Fig. S2 $\dagger)$. MS (FT-ICR): $\mathrm{C}_{30} \mathrm{H}_{24} \mathrm{~N}_{6} \mathrm{O}_{2} \mathrm{~S}_{2}\left[\mathrm{M}^{+}\right]$564.14; found $565.15(\mathrm{Mz})$ with the isotopic patterns for the corresponding molecular ions (Fig. S3†). ${ }^{1} \mathrm{H}$ NMR (400 MHz, DMSO- $\left.d_{6}\right) \delta 11.47$ (s, 2H), 10.19 $(\mathrm{s}, 2 \mathrm{H}), 8.55(\mathrm{~s}, 2 \mathrm{H}), 8.27-7.95(\mathrm{~m}, 6 \mathrm{H}), 7.73-7.63(\mathrm{~m}, 4 \mathrm{H}), 7.46$ (d, $J=8.3 \mathrm{~Hz}, 4 \mathrm{H}), 7.02-6.82(\mathrm{~m}, 4 \mathrm{H})$ (Fig. S5 $\dagger$ ). Elemental analysis: measuring result (\%): C (64.20), H (4.03), N (14.48), $\mathrm{S}$ (11.04); calculated result (\%): C (63.83), H (4.29), N (14.88), $\mathrm{S}$ (11.33).

\section{Preparation of UC solutions}

DHTPA (60 mM) and PdOEP (30 mM) were dissolved in mixed solvents of $10 \mathrm{~mL}$ DMF and $5 \mathrm{~mL}$ water as a stock solution. Then the solution was nitrogen-bubbled for $40 \mathrm{~min}$ and then sealed and stored in dark for further measurements. 


\section{Detection of the $\mathrm{Fe}^{3+}$ ions by a TTA-UC ratiometric sensor}

The TTA-UC based ratiometric sensor was formed by the double-dye TTA-UC solution consisting of responsive annihilator DHTPA and sensitizer PdOEP. Different amount of $\mathrm{Fe}^{3+}$ ions were added into the TTA-UC solution to build environment with varying $\mathrm{Fe}^{3+}$ concentrations, respectively. UC spectrum of each sample excited by a CW $532 \mathrm{~nm}$ laser $(60 \mathrm{~mW}$ power and $2 \mathrm{~mm}$ beam diameter) was recorded after $10 \mathrm{~min}$ of reaction. The peak area integrations of UC $(458 \mathrm{~nm})$ and PL (665 nm) emissions in all the spectra were calculated.

For a contrast experiment, the typical fluorescence spectra of DHTPA excited by $398 \mathrm{~nm}$ UV light under different $\mathrm{Fe}^{3+}$ concentrations were also recorded after $10 \mathrm{~min}$ of reaction. The peak area integrations of fluorescent ( $455 \mathrm{~nm}$ ) emissions in all the spectra were calculated.

The $\mathrm{pH}$ responsiveness of the TTA-UC ratiometric sensor was measured under different $\mathrm{pH}$ environment $(\mathrm{pH}=4-11)$. The $\mathrm{pH}$ value was adjusted by adding different amount of hydrogen chloride or sodium hydroxide in the solution. All the UC spectra of different conditions were recorded and the peak area integrations of UC were calculated and compared.

The selectivity for $\mathrm{Fe}^{3+}$ ions was measured by adding other types of metal ions $\left(\mathrm{Mn}^{2+}, \mathrm{NH}_{4}{ }^{+}, \mathrm{Zn}^{2+}, \mathrm{Mg}^{2+}, \mathrm{Cd}^{2+}, \mathrm{Pb}^{2+}, \mathrm{Li}^{+}, \mathrm{Na}^{+}\right.$, $\mathrm{K}^{+}, \mathrm{Ag}^{+}, \mathrm{Ca}^{2+}$ ) into the TTA-UC solution after $10 \mathrm{~min}$ of reaction, respectively. The concentration of different metal ions in these samples were all the same. It should be pointed out that except silver nitrate, soluble chlorides were also added in this step to avoid the influence of anions. All detection experiments were performed at room temperature. In order to avoid the influence of changing $\mathrm{pH}$ values, which are caused by different types of metal salts, on the UC intensities of the detecting sample, proper amount of buffer solution was added into the system.

\section{Results and discussion}

Fig. 1 shows the synthetic route of DHTPA. The intermediate compound DHAPA was synthesized through a Suzuki coupling reaction between 4-bromo-2-hydroxybenzaldehyde and 9,10anthracenediboronic acid bis(pinacol) ester. The IR spectrum and ${ }^{1}$ HNMR spectrum are revealed in Fig. $\mathrm{S} 1$ and $\mathrm{S} 4, \dagger$ respectively. Subsequently, aldehyde-ammonia condensation reaction between DHAPA and thiosemicarbazide occurred and yielded the responsive annihilator DHTPA. The IR spectrum, mass spectrum and ${ }^{1}$ HNMR spectrum are shown in Fig. S2, S3 and $\mathrm{S} 5, \dagger$ respectively.

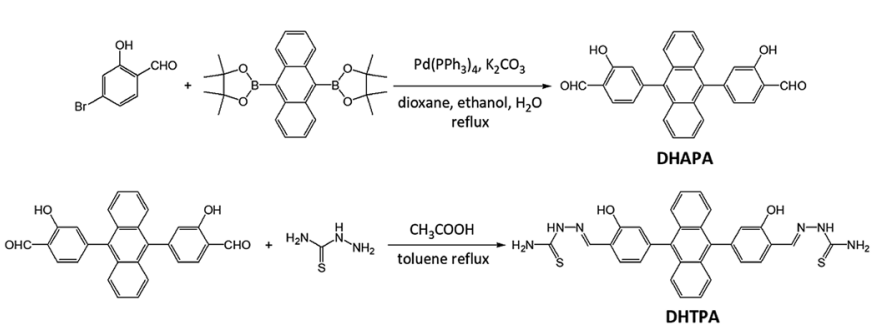

Fig. 1 Schematic illustration of the synthetic route of DHTPA.
The normalized absorption and steady-state photoluminescence spectra of DHTPA and PdOEP in DMF are shown in Fig. 2. There are three main peaks (344, 378 and $398 \mathrm{~nm}$ ) in the absorption spectra of DHTPA (Fig. 2a). The probe molecule DHTPA exhibits one-peak fluorescent emission at $455 \mathrm{~nm}$. Fig. 2b shows that as a classic metalloporphyrin complex sensitizer, PdOEP possesses a Soret absorption band at $395 \mathrm{~nm}$ and a Q-band at $547 \mathrm{~nm}$ and also reveals PL emission at $655 \mathrm{~nm}$ when excited by a $532 \mathrm{~nm}$ laser.

UC spectrum of DHTPA/PdOEP solution is shown in Fig. 3. The UC emission is at $458 \mathrm{~nm}$ under excitation of $532 \mathrm{~nm}$, and meanwhile the PL emission of PdOEP is at $665 \mathrm{~nm}$. To enhance the absolute intensity of UC emission from DHTPA and obtain a relatively higher SNR (signal to noise ratio) for the sensor, the ratio of PdOEP/DHTPA was investigated by fixing DHTPA concentration and increasing PdOEP concentration (Fig. S6 $†$ ). The ratio of PdOEP/DHTPA was $1: 2$ when UC intensity reached the maximum. In order to eliminate the disturbance of $\mathrm{pH}$ changing during the detection of metal ions and to find an optimal operating condition, the integrated UC intensity of DHTPA/PdOEP system at different $\mathrm{pH}$ environments were measured and shown in the inset of Fig. 3. It is found that the UC intensity nearly remains constant and maximal under the $\mathrm{pH}$ from 6 to 9, which reveals that the sensor can be fully functional in a relatively broad neutral $\mathrm{pH}$ range, exhibiting a possibility of applications in biological field.

The UC emission spectra of DHTPA/PdOEP system at environments of different concentration of $\mathrm{Fe}^{3+}$ ions are shown in Fig. 4a. All the spectra were recorded after the spectral signals are stable, since the reaction between DHTPA and $\mathrm{Fe}^{3+}$ ions would stop in $10 \mathrm{~min}$ (Fig. $\mathrm{S} 7 \dagger$ ). As a result, the $\mathrm{Fe}^{3+}$ ions have a great quenching effect on UC emission and meanwhile barely no influence on PL emission. Before adding $\mathrm{Fe}^{3+}$ ions, the blank sample displays purple emission light when excited by $532 \mathrm{~nm}$ laser. As the $\mathrm{Fe}^{3+}$ ions are added, the UC emission is effectively quenched and emission colour turn into red (insets of Fig. 4c). The obvious colour change can be easily distinguished by naked eyes. Interestingly, both the UC and PL emission intensities
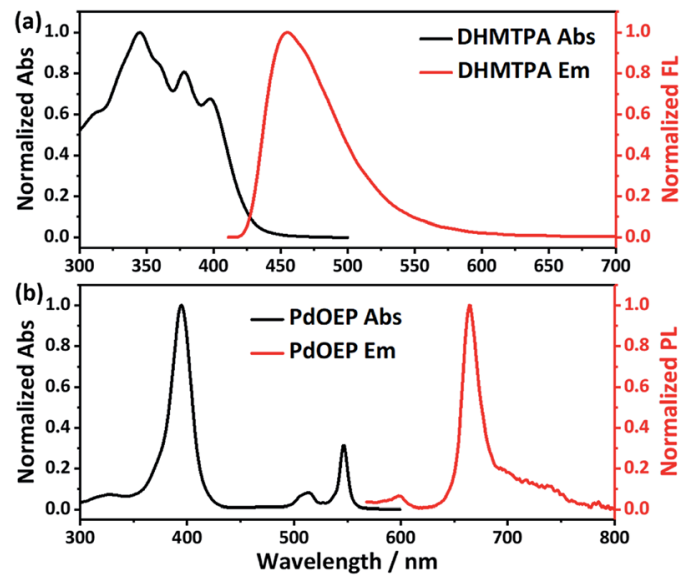

Fig. 2 Normalized absorption and steady-state photoluminescence spectra of (a) DHTPA and (b) PdOEP in DMF at room temperature. 


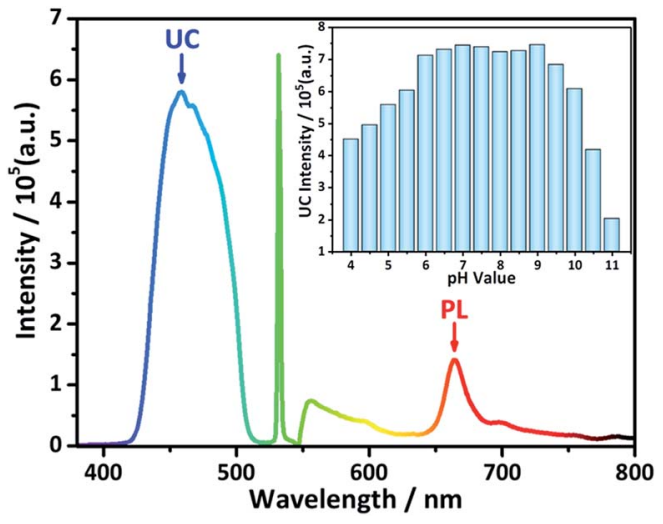

Fig. 3 UC emission spectrum of DHTPA/PdOEP system; inset: histogram of integrated $U C$ intensity under different $\mathrm{pH}$ environments.

reveal good linear relationships with concentration of $\mathrm{Fe}^{3+}$ ions (Fig. 4b), which makes the DHTPA/PdOEP TTA-UC system a perfect candidate for ratiometric sensors. Particularly, the PL intensity shows nearly no change through the concentration increasing of $\mathrm{Fe}^{3+}$ ions, making it a very appropriate internal reference for UC signal. Finally, a good linear relationship $\left(R^{2}=\right.$ $0.995)$ between ratio intensity $\left(I_{\mathrm{UC}} / I_{\mathrm{PL}}\right)$ and $\mathrm{Fe}^{3+}$ concentration $(0-9 \mu \mathrm{M})$ is shown in Fig. 4c, yielding an effective ratiometric sensor for $\mathrm{Fe}^{3+}$ ion detection (Fig. 4d). As shown in Fig. 4d, the TTET process still existed after adding $\mathrm{Fe}^{3+}$ ions into the system, which can be verified by Fig. S8 and S9. $\dagger$ When varying the amount of added $\mathrm{Fe}^{3+}$ ions $(0-10 \mu \mathrm{M})$, the absorption spectra of DHTPA are almost constant (Fig. S8 $\dagger$ ). The changing of PL lifetime of PdOEP can reflect the environments in the solution
(Fig. S9†). When only PdOEP was added in the solution, the PL lifetime was relatively long. After adding DHTPA, the PL lifetime reduced obviously due to the emerging of TTET process. At last, $\mathrm{Fe}^{3+}$ ions $(10 \mu \mathrm{M})$ were added into the solution, and the PL lifetime did not change much. If the TTET can be blocked by $\mathrm{Fe}^{3+}$ ions, the PL lifetime should increase obviously. In that case, the $\mathrm{Fe}^{3+}$ ions do not affect the TTET process, which also provides evidence to contant PL intensity.

The limit of detection (LOD) of this ratiometric sensor is 7.26 $\times 10^{-7} \mathrm{M}$, calculated by using eqn (S1). $\dagger$ Because of the presence of internal reference, ratiometric sensors can eliminate the negative influence from the devices, environment or probes themselves on the detecting results, improving the selectivity, sensitivity and stability of the sensor. ${ }^{29}$

In order to further prove the responsive nature of DHTPA to $\mathrm{Fe}^{3+}$ ions, the fluorescent emission of DHTPA dependent on $\mathrm{Fe}^{3+}$ ions is also investigated, and the results are shown in Fig. S10. $\dagger$ The fluorescence of DHTPA can also be quenched by $\mathrm{Fe}^{3+}$ ions $(0-9 \mu \mathrm{M})$, and its intensity exhibits good linear relationship with $\mathrm{Fe}^{3+}$ concentration, yielding a normal onechannel $\mathrm{Fe}^{3+}$ sensor based on a fluorescent probe. The binding constant $K_{\mathrm{a}}$ of the complexing reaction derived from titration data in Fig. 4a and S6 $\dagger$ are calculated based on BenesiHildebrand equation (Fig. S11†). ${ }^{30}$ The $K_{\mathrm{a}}$ from the UC signal is $2.218 \times 10^{4} \mathrm{M}^{-1}$, while the $K_{\mathrm{a}}$ from the FL signal is $2.536 \times 10^{4}$ $\mathrm{M}^{-1}$. The similar $K_{\mathrm{a}}$ indicates that although different probes were used for $\mathrm{Fe}^{3+}$ sensing, the reaction between the metal ions and DHTPA is pretty much the same in the two situations.

The selectivity of the ratiometric sensor is shown in Fig. 5. The responsiveness of UC emission of DHTPA/PdOEP system to twelve types of metal ions $\left(\mathrm{Fe}^{3+}, \mathrm{Mn}^{2+}, \mathrm{NH}^{4+}, \mathrm{Zn}^{2+}, \mathrm{Mg}^{2+}, \mathrm{Cd}^{2+}\right.$,

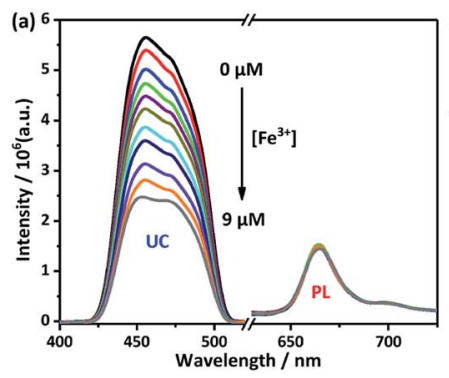

(d)
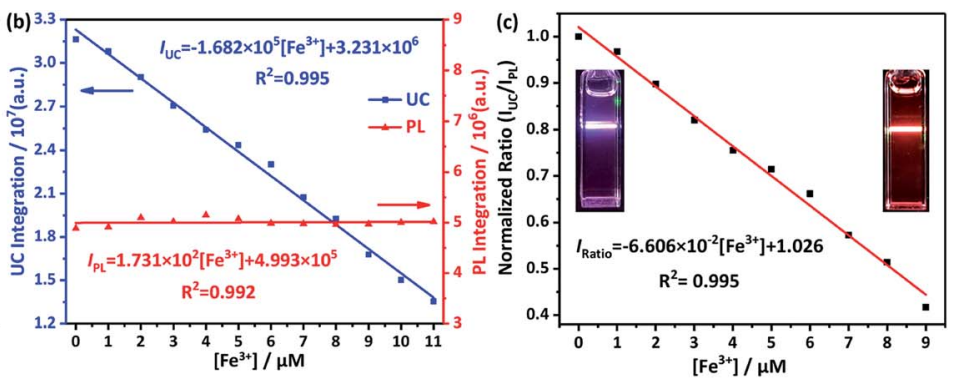

UC Quenched

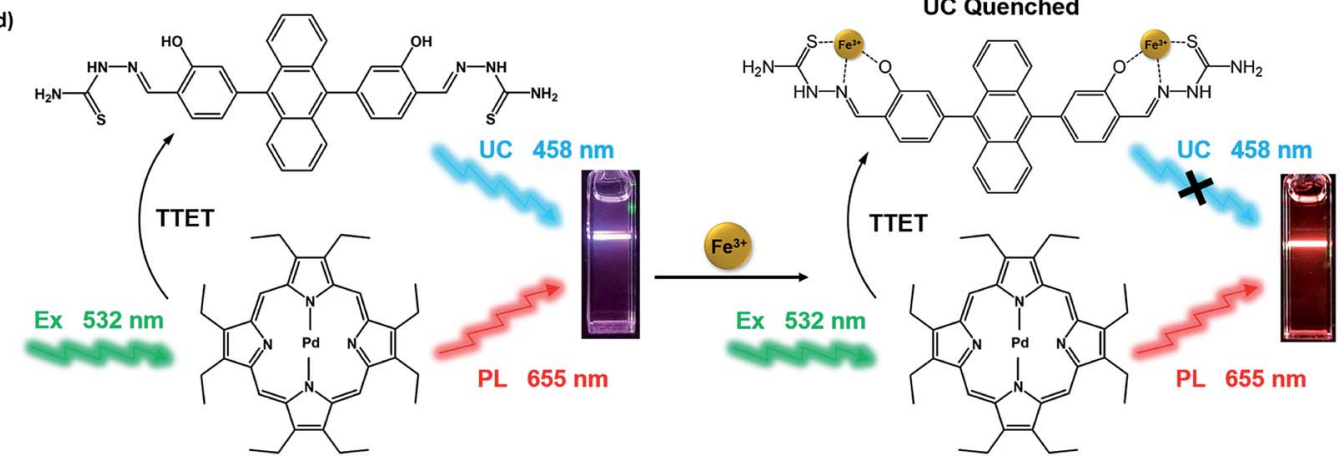

Fig. 4 (a) UC emission spectra of DHTPA/PdOEP system at environments of different concentrations of Fe ${ }^{3+}$ ions; (b) plot of integrated intensities of $U C$ and $\mathrm{PL}$ in (a) dependent on concentration of $\mathrm{Fe}^{3+}$ ions; (c) plot of ratio intensities (/UC//PL) dependent on concentration of Fe ${ }^{3+}$ ions; insets: photographs of purple emission from blank sample without $\mathrm{Fe}^{3+}$ ions (left) and red emission from sample with $10 \mu \mathrm{M} \mathrm{Fe}{ }^{3+}$ ions (right) under excitation of $532 \mathrm{~nm}$ through an optical filter (d) mechanism of the ratiometric sensor based on TTA-UC. 


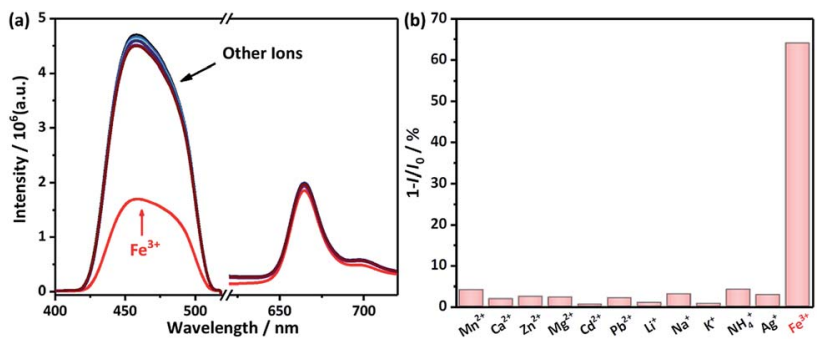

Fig. 5 (a) UC emission spectra of DHTPA/PdOEP system at environments of different types of metal ions $(10 \mu \mathrm{M})$; (b) histogram of quenching ratio calculated from UC emissions in (a).

$\left.\mathrm{Pb}^{2+}, \mathrm{Li}^{+}, \mathrm{Na}^{+}, \mathrm{K}^{+}, \mathrm{Ag}^{+}, \mathrm{Ca}^{2+}\right)$ is thoroughly studied. The results show that among those metal ions, only $\mathrm{Fe}^{3+}$ has a significant quenching effect on the UC emission (Fig. 5a). The quenching ratio of the $\mathrm{Fe}^{3+}$ ions is up to $64.8 \%$, while no other metal ions are more than $4 \%$ (Fig. $5 \mathrm{~b}$ ), which shows a highly selectivity of the ratiometric sensor to $\mathrm{Fe}^{3+}$ among 12 types of metal ions.

The mechanism of the responsiveness of UC emission to $\mathrm{Fe}^{3+}$ ions is due to the complexation between $\mathrm{Fe}^{3+}$ and DHTPA, which turned the fluorescent " $D-\pi-D$ " structure into nonfluorescent "A- $\pi-\mathrm{A}$ " structure. The selectivity reveals that $\mathrm{Fe}^{3+}$ ions have stronger complex strength and faster complex reaction dynamics, yielding the DHTPA/PdOEP TTA-UC system a highly selective and effective ratiometric sensor for $\mathrm{Fe}^{3+}$ ions.

For the future perspective, since the oxygen sensitivity is an unavoidable issue in TTA-UC system, solutions must be considered to develop TTA-UC based ratiometric sensor with long term stability. So far great efforts have been made in solidstate UC materials and deoxygenating solvents, ${ }^{24}$ which will authentically make the TTA-UC material a promising candidate for sensing applications.

\section{Conclusions}

In conclusion, we designed and synthesized a new responsive annihilator DHTPA to form a TTA-UC system by combining PdOEP as sensitizer. When excited by a $532 \mathrm{~nm}$ green laser, blue UC emission and red PL emission were simultaneously obtained from the TTA-UC system. Because of the complexation between DHTPA and $\mathrm{Fe}^{3+}$ ions, UC emission can be significantly quenched and show linear relationship with $\mathrm{Fe}^{3+}$ concentration increasing. Meanwhile, the PL showed no responsive behaviour to $\mathrm{Fe}^{3+}$ ions and remained constant. By regarding $\mathrm{PL}$ signal as an internal reference for UC signal, the TTA-UC system can be employed as a ratiometric sensor for the detection of $\mathrm{Fe}^{3+}$ ions. The ratio signal also revealed good linear relationship $\left(R^{2}=0.995\right)$ with $\mathrm{Fe}^{3+}$ concentration $(0-9 \mu \mathrm{M})$. The LOD of the ratiometric sensor is $7.26 \times 10^{-7} \mathrm{M}$, and it showed highly selectivity to $\mathrm{Fe}^{3+}$ ions among twelve types of metal ions. The double-chromophore nature of TTA-UC system exhibited multiple emissions with different responsive behaviour, making it a perfect candidate for ratiometric sensor. This sensing method will provide a new angle for preparing ratiometric sensors for applications in many areas.

\section{Conflicts of interest}

There are no conflicts to declare.

\section{Acknowledgements}

This work was supported by National Natural Science Foundation of China (Grant No. 51603141, 51873145, 51673143); Natural Science Foundation of Jiangsu Province (BK20160358); Natural Science Foundation of Jiangsu Province Excellent Youth Foundation (BK20170065); Natural Science Foundation of the Higher Education Institutions of Jiangsu Province; 5th 333 High-level Talents Training Project of Jiangsu Province (No. BRA2018340); Six Talent Summits Project of Jiangsu Province (No. XCL-79); Qing Lan Project; Suzhou Key Laboratory for Nanophotonic and Nanoelectronic Materials and Its Devices (SZS201812).

\section{References}

1 B. L. Logeman and D. J. Thiele, J. Biol. Chem., 2018, 293, 15497; Y. Z. Lu, L. Fu, N. Li, J. Ding, Y. N. Bai, P. Samaras and R. J. Zeng, Chemosphere, 2018, 198, 370; X. W. Huang, É. Boutroy, S. Makvandi, G. Beaudoin, L. Corriveau and A. F. D. Toni, Miner. Deposita, 2019, 54, 525.

2 Y. Peng, H. Huang, Y. Zhang, C. Kang, S. Chen, L. Song, D. Liu and C. Zhong, Nat. Commun., 2018, 9, 187.

3 G. Mun, S. H. Jung, A. Ahn, S. S. Lee, M. Y. Choi, D. H. Kim, J. Y. Kim and J. H. Jung, RSC Adv., 2016, 6, 53912; A. Yazdanpanah, D. S. M. Ghasimi, G. K. Min, G. Nakhla, H. Hafez and M. Keleman, Environ. Sci. Pollut. Res., 2018, 25, 29240; P. A. Sharp, B. Sugden and J. Sambrook, Biochemistry, 1973, 12, 3055; M. Tsubaki, R. B. Srivastava and N. T. Yu, Biochemistry, 1982, 21, 1132; F. W. Outten and O. G. Djaman, Mol. Microbiol., 2010, 52, 861.

4 T. A. Rouault, Nat. Chem. Biol., 2006, 2, 406.

5 L. Zecca, M. B. Youdim, P. Riederer, J. R. Connor and R. R. Crichton, Nat. Rev. Neurosci., 2004, 5, 863.

6 S. Mandel, T. Amit, O. Baram and M. B. Youdim, Prog. Neurobiol., 2007, 82, 348.

7 D. Benshachar, P. Riederer and M. B. Youdim, J. Neurochem., 2010, 57, 1609.

8 A. M. Martinez, A. Støre and K. S. Osen, Metall. Mater. Trans. $B, 2018,49,783$.

9 L. Kai, L. Yao, W. Fang, J. Ren and H. Xie, Constr. Build. Mater., 2018, 178, 144.

10 B. V. D. Grift, L. Osté, P. Schot, A. Kratz, E. V. Popta, M. Wassen and J. Griffioen, Sci. Total Environ., 2018, 631632, 115.

11 Q. Zhang, Z. Wei, Y. Cui, C. Lyu, L. Tong, R. Zhang, Z. Rui, J. Zheng, Z. Shi and C. Lu, Environ. Sci.: Nano, 2018, 5, 246.

12 B. Haghighi and A. Safavi, Anal. Chim. Acta, 1997, 354, 43.

13 R. C. d. C. C. A. NovaAraújo, Anal. Chim. Acta, 2001, 438, 227.

14 S. Thatai, P. Khurana, S. Prasad and D. Kumar, Microchem. J., 2014, 113, 77.

15 J. Yu, C. Liu, K. Yuan, Z. Lu, Y. Cheng, L. Li, X. Zhang, P. Jin, F. Meng and H. Liu, Nanomaterials, 2018, 8, 233. 
16 Y. c. Gonül, S. Elif, D. Mahmut, Y. Fatma and K. Adem, Dalton Trans., 2013, 42, 14916.

17 D. Song, E. Ma, Z. M. Sun and H. Zhang, J. Mater. Chem., 2012, 22, 16920; C. X. Yang, H. B. Ren and X. P. Yan, Anal. Chem., 2013, 85, 7441; M. Zhu, C. Shi, X. Xu, Z. Guo and W. Zhu, RSC Adv., 2016, 6, 100759; J. Li, Q. Wang, Z. Guo, H. Ma, Y. Zhang, B. Wang, B. Du and Q. Wei, Sci. Rep., 2016, 6, 23558.

18 M. Zhao, X. Zhou, J. Tang, Z. Deng, X. Xu, Z. Chen, X. Li, L. Yang and L. J. Ma, Spectrochim. Acta, Part A, 2017, 173, 235.

19 J. Nakai, M. Ohkura and K. Imoto, Nat. Biotechnol., 2001, 19, 137.

20 Y. Zhou, E. M. Marcus, R. P. Haugland and M. Opas, J. Cell. Physiol., 2010, 164, 9.

21 Y. Chen, T. Zhang, X. Gao, W. Pan, N. Li and B. Tang, Chin. Chem. Lett., 2017, 28, 1983.

22 J. Zhao, S. Ji and H. Guo, RSC Adv., 2011, 1, 937; S. Liu, S. Liu, M. Zhou, X. Ye, D. Hou and W. You, RSC Adv., 2017, 7, 36935; Q. Zhang, Z. Han, J. Tao, W. Zhang, P. Li, L. Tang and Y. Gu, J. Biophotonics, 2018, 11, 1; L. J. Xiang, H. H. Zhang, H. Li, L. Kong, H. P. Zhou, J. Y. Wu, Y. P. Tian, J. Zhang and Y. F. Mao, Nanoscale, 2017, 9, 18861; C. Ye, J. Ma, P. Han, S. Chen, P. Ding, B. Sun and X. Wang, RSC Adv., 2019, 9, 17691.
23 X. Yang, J. Han, Y. Wang and P. Duan, Chem. Sci., 2019, 10, 172; D. Yang, P. Duan and M. Liu, Angew. Chem., Int. Ed., 2018, 57, 9357.

24 J. Ma, S. Chen, C. Ye, M. Li, T. Liu, X. Wang and Y. Song, Phys. Chem. Chem. Phys., 2019, 21, 14516; W. Bao, B. Sun, X. Wang, C. Ye, D. Ping, Z. Liang, Z. Chen, X. Tao and L. Wu, J. Phys. Chem. C, 2014, 118, 141; C. Ye, J. Wang, X. Wang, P. Ding, Z. Liang and X. Tao, Phys. Chem. Chem. Phys., 2016, 18, 3430; C. Ye, L. Zhou, X. Wang and Z. Liang, Phys. Chem. Chem. Phys., 2016, 18, 10818.

25 C. Ye, J. Ma, S. Chen, G. Jie and Y. Zhou, J. Phys. Chem. C, 2017, 121, 20158; C. Ye, S. Chen, F. Li, J. Ge, P. Yong, M. Qin and Y. Song, Acta Chim. Sinica, 2018, 76, 237.

26 R. Zhang, F. Yan, Y. Huang, D. Kong, Q. Ye, J. Xu and L. Chen, $R S C A d v .$, 2016, 6, 50732.

27 S. M. Borisov, C. Larndorfer and I. Klimant, Adv. Funct. Mater., 2012, 22, 4360.

28 M. Xu, X. Zou, Q. Su, W. Yuan, C. Cao, Q. Wang, X. Zhu, W. Feng and F. Li, Nat. Commun., 2018, 9, 2698; N. Nazarova, Y. Avlasevich, K. Landfester and S. Baluschev, ChemPhotoChem, 2019, 3, 1.

29 P. Xiaojun, Y. Zhigang, W. Jingyun, F. Jiangli, H. Yanxia, S. Fengling, W. Bingshuai, S. Shiguo, Q. Junle and Q. Jing, J. Am. Chem. Soc., 2011, 133, 6626.

30 H. A. Benesi and J. H. Hildebrand, J. Am. Chem. Soc., 1949, 71, 2703. 